with interarterial course and no intramural component, we favor pulmonary artery translocation to create space between the aortic and pulmonic roots, thereby decreasing the risk of pulmonary compression of the coronary artery. ${ }^{7}$ Intraoperative inspection determines which procedure will be performed. If the orientation of the aortic and pulmonic roots is such that anterior movement of the MPA will create space, a LeCompte maneuver is done. Alternatively, if moving the MPA laterally will create space, the MPA is translocated distally toward the left pulmonary artery.

At the current time there is not sufficient data to form firm management guidelines for asymptomatic children with ACAs from the contralateral sinus. Because of the documented risk of sudden death without antecedent symptoms, our policy is to surgically correct all lesions at risk, regardless of symptoms. Although we believe pulmonary artery translocation is protective of subsequent ischemic episodes, long-term follow-up has not been achieved. Whether it will reduce subsequent risk of myocardial ischemia or sudden cardiac death remains to be determined.

\section{References}

1. Laureti JM, Singh K, Blankenship J. Anomalous coronary arteries: a familial clustering. Clin Cardiol. 2005;28:488-90.

2. Brothers JA, Stephens P, Gaynor JW, Lorber R, Vricella LA, Paridon SM. Anomalous aortic origin of a coronary artery with an interarterial course: should family screening be routine? J Am Coll Cardiol. 2008;51:2062-4.

3. Yamanaka O, Hobbs RE. Coronary artery anomalies in 126,595 patients undergoing coronary arteriography. Cathet Cardiovasc Diagn. 1990;21:28-40.

4. Davis JA, Cecchin F, Jones TK, Portman MA. Major coronary artery anomalies in a pediatric population: incidence and clinical importance. J Am Coll Cardiol. 2001;37:593-7

5. Taylor AJ, Rogan KM, Virmani R. Sudden cardiac death associated with isolated congenital coronary artery anomalies. J Am Coll Cardiol. 1992;20:640-7.

6. Gulati R, Reddy VM, Culbertson C, Helton G, Suleman S, Reinhartz O, et al. Surgical management of coronary artery arising from the wrong coronary sinus, using standard and novel approaches. J Thorac Cardiovasc Surg. 2007;134:1171-8.

7. Rodefeld MD, Culbertson CB, Rosenfeld HM, Hanley FL, Thompson LD. Pulmonary artery translocation: a surgical option for complex anomalous coronary artery anatomy. Ann Thorac Surg. 2001;72:2150-2.

\title{
Quadruple valve replacement in patients with carcinoid heart disease
}

\author{
Arman Arghami, MD, ${ }^{\mathrm{a}}$ Heidi M. Connolly, MD, ${ }^{\mathrm{b}}$ Martin D. Abel, MD, ${ }^{\mathrm{c}}$ and Hartzell V. Schaff, MD, ${ }^{\mathrm{a}}$ \\ Rochester, Minn
}

Carcinoid is a rare tumor of neuroendocrine cell lineage that occurs in 1.2 to 2.1 persons per 100,000 per year. ${ }^{1}$ At diagnosis, $20 \%$ to $30 \%$ of patients have disseminated disease and consequent carcinoid syndrome. ${ }^{2}$ Carcinoid heart disease affects $40 \%$ of patients and remains a source of major morbidity and mortality in carcinoid syndrome. Heart involvement is thought to occur when serotonin and other active substances are released from hepatic metastases or primary ovarian carcinoid tumors, thus bypassing metabolism in the liver.

Carcinoid heart disease typically involves tricuspid and pulmonary valves, and patients often present with signs and symptoms of right heart failure. Left-sided valve involvement is reported infrequently $(<10 \%$ of patients with carcinoid heart disease $)^{1}$ and is possibly due to metabolism of active substances by the lung. Thus, carcinoid

From the Divisions of Cardiovascular Surgery, ${ }^{\text {a }}$ Cardiovascular Diseases, ${ }^{\text {b }}$ and Cardiovascular and Thoracic Anesthesia, ${ }^{\mathrm{c}}$ Mayo Clinic, Rochester, Minn.

Disclosures: None.

Received for publication Feb 11, 2010; revisions received April 14, 2010; accepted for publication May 14, 2010; available ahead of print June 28, 2010.

Address for reprints: Hartzell V. Schaff, MD, Division of Cardiovascular Surgery,

Mayo Clinic, 200 First St SW, Rochester MN 55905 (E-mail: schaff@ mayo.edu).

J Thorac Cardiovasc Surg 2010;140:1432-4

$0022-5223 / \$ 36.00$

Copyright (C) 2010 by The American Association for Thoracic Surgery

doi:10.1016/j.jtcvs.2010.05.026 disease of the mitral and aortic valves may occur more frequently in patients with an atrial septal defect or patent foramen ovale (PFO) with right-to-left shunting of blood. Left heart involvement may also occur in the absence of an intracardiac shunt, perhaps with bronchopulmonary carcinoid or high levels of circulating serotonin. ${ }^{3}$ We describe our experience with 7 patients who, because of carcinoid heart disease, underwent quadruple valve replacement.

\section{CLINICAL SUMMARY}

Between July 1989 and April 2010, 7 patients underwent quadruple valve replacement for carcinoid heart disease at Mayo Clinic, Rochester, Minnesota. This group comprised $4 \%$ of 168 patients who had valve surgery for carcinoid heart disease and $23 \%$ of the 30 patients with concomitant involvement of the mitral or aortic valves.

\section{RESULTS}

All patients had clinical signs and symptoms of right and left heart failure and echocardiographic evidence of carcinoid heart disease, including thickened valves with regurgitation. Right-sided valves had more severe involvement than left except for 1 patient who had moderate tricuspid regurgitation and severe regurgitation affecting the 3 other valves. Intraoperative echocardiography identified a PFO 
TABLE 1. Outcomes of 7 patients with carcinoid heart disease who underwent quadruple valve replacement

\begin{tabular}{|c|c|c|c|c|c|c|c|c|c|c|c|}
\hline \multirow[b]{2}{*}{ Patient } & \multirow{2}{*}{$\begin{array}{c}\text { Age, } \\
\mathbf{y}\end{array}$} & \multirow[b]{2}{*}{ Gender } & \multirow{2}{*}{$\begin{array}{l}\text { Maximum } \\
\text { 5-HIAA, } \\
\text { mg/24 h }\end{array}$} & \multicolumn{2}{|c|}{ NYHA } & \multirow{2}{*}{$\begin{array}{l}\text { Year of } \\
\text { surgery }\end{array}$} & \multirow[b]{2}{*}{ PFO } & \multirow{2}{*}{$\begin{array}{c}\text { CBP } \\
\text { time, } \min \end{array}$} & \multirow{2}{*}{$\begin{array}{l}\text { Crossclamp, } \\
\min \end{array}$} & \multirow{2}{*}{$\begin{array}{l}\text { Prosthesis } \\
\text { type }\end{array}$} & \multirow[b]{2}{*}{ Survival } \\
\hline & & & & Preoperative & Postoperative & & & & & & \\
\hline 1 & 59 & M & 517 & 3 & 2 & 1989 & No & 173 & 104 & $\begin{array}{l}\text { St Jude Ć(St Jude Medical, } \\
\text { Inc, St Paul, MN) plus PH }\end{array}$ & $39 \mathrm{mo}$ \\
\hline 2 & 61 & M & 468 & 4 & Died & 1999 & No & 157 & 67 & St Jude & $6 \mathrm{~d}$ \\
\hline 3 & 79 & M & 170 & 3 & 2 & 2002 & Yes & 122 & 59 & $\begin{array}{l}\text { Carpentier-Edwards } \\
\text { (Edwards Lifesciences, } \\
\text { LLC, Irvine, CA) }\end{array}$ & $5 \mathrm{mo}$ \\
\hline 4 & 51 & M & 475 & 3 & 1 & 2006 & Yes & 61 & 7 & CarboMedics, Inc, Austin, TX & $30 \mathrm{mo}$ \\
\hline 5 & 69 & $\mathrm{~F}$ & 21.8 & 2 & 1 & 2009 & No & 200 & 75 & St Jude & $\begin{array}{l}\text { Alive at FU } \\
\qquad(6 \mathrm{mo})\end{array}$ \\
\hline 6 & 61 & M & 192 & 3 & 2 & 2009 & Yes & 107 & 59 & St Jude & $\begin{array}{l}\text { Alive at FU } \\
\quad(4 \mathrm{mo})\end{array}$ \\
\hline 7 & 52 & $\mathrm{~F}$ & 118 & 3 & 2 & 2009 & No & 133 & 67 & CarboMedics, Inc & $\begin{array}{l}\text { Alive at FU } \\
\qquad(3 \mathrm{mo})\end{array}$ \\
\hline
\end{tabular}

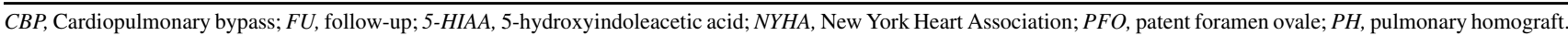

with right-to-left shunting in 3 patients $(43 \%)$ that was surgically confirmed and repaired. Notably, no defects were detected on preoperative transthoracic echocardiograms.

All patients had increased concentrations of urinary 5-hydroxyindoleacetic acid; levels were similar in patients with or without a PFO (Table 1). Urinary 5-hydroxyindoleacetic acid was only $21.8 \mathrm{mg} / 24$ hours in the sole patient (patient 5, Table 1) with primary ovarian carcinoid tumor.

\section{Surgical Management}

Six patients underwent replacement of all 4 valves during 1 operation; 1 patient (patient 4 ) had aortic and mitral valves replaced with mechanical prostheses at another institution for what was initially thought to be rheumatic heart disease. Subsequently, he was found to have metastatic carcinoid with right heart involvement and underwent tricuspid and pulmonary valve replacement at the Mayo Clinic. Right ventricular outflow tract reconstruction (pulmonary augmentation) with pericardial patch was performed in 5 $(71 \%)$ of 7 patients. During surgery, 6 patients received octreotide (median dose, $1.5 \mathrm{mg}$ [range, 0.8-4 mg]). Supplemental octreotide was used in 3 patients during their stay in intensive care (median dose, $2.3 \mathrm{mg}$ [range, 0.5-5.2 mg]). All excised valves had clinical and pathologic findings consistent with carcinoid heart disease.

\section{Surgical Outcomes}

Four $(57 \%)$ of the 7 patients had postoperative cardiac arrhythmias ( 2 with atrial fibrillation; 2 with heart block), and 1 patient required permanent pacing. One patient with a preoperative creatinine concentration of $3.3 \mathrm{mg} / \mathrm{dL}$ had transient worsening of renal insufficiency postoperatively but did not require dialysis.

\section{Follow-up Data}

One patient died of heart failure 6 days postoperatively. Functional improvement (eg, increased exercise tolerance, reduced lower extremity edema, reduced ascites, resolution of orthopnea, and paroxysmal nocturnal dyspnea) was noted in all survivors. At last follow-up, left ventricular

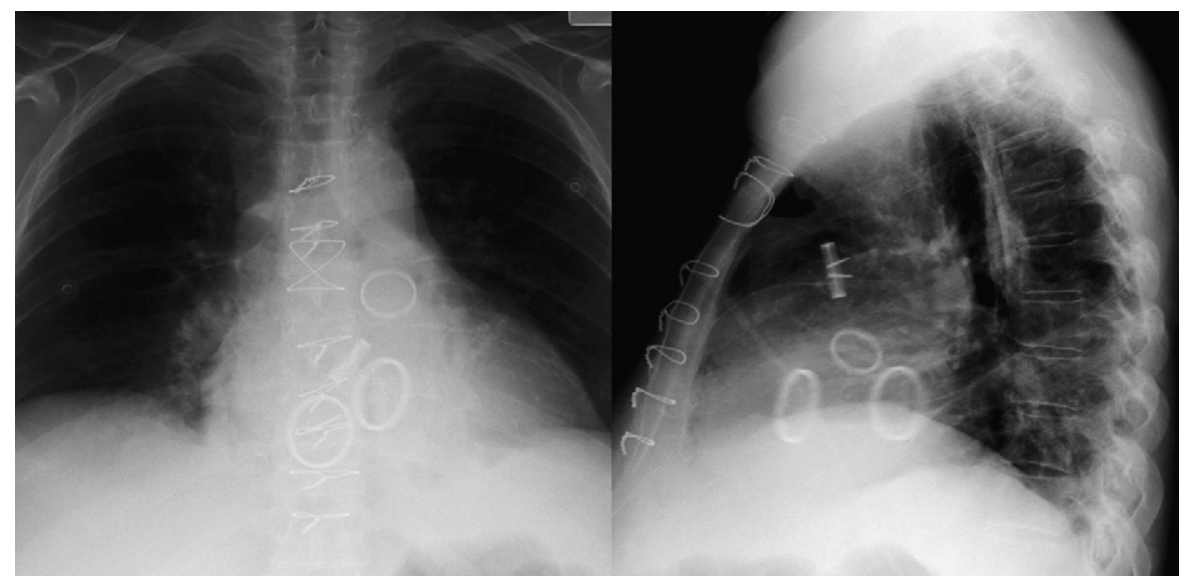

FIGURE 1. Posteroanterior and lateral chest radiographs of a patient with carcinoid heart disease after quadruple valve replacement. 
end-diastolic diameter was improved in 5 patients; right ventricular size and function improved in 3 patients. Three late deaths due to carcinoid progression occurred postoperatively at 39,5 , and 30 months.

\section{DISCUSSION}

Previous studies have shown that tricuspid and pulmonary valve replacement can improve symptoms and survival in patients with right heart failure due to carcinoid heart disease. ${ }^{1}$ Improved functional status and cardiac chamber size were also noted in our carcinoid patients with 4 valve replacements. Notably, a PFO was present in only 3 patients, and each was detected only by intraoperative transesophageal echocardiography with saline injection. Thus, our experience documents that an intracardiac shunt is not necessary for development of left-sided carcinoid valve disease, despite other reports. ${ }^{4,5}$

\section{CONCLUSIONS}

Although carcinoid heart disease with involvement of all 4 valves is rare, we conclude that quadruple valve replacement in symptomatic patients is a reasonable option that can result in functional improvement with acceptable risks.

\section{References}

1. Connolly HM, Schaff HV, Mullany CJ, Rubin J, Abel MD, Pellikka PA. Surgical management of left-sided carcinoid heart disease. Circulation. 2001;104(12 Suppl. 1):I36-40

2. Castillo JG, Filsoufi F, Rahmanian PB, Anyanwu A, Zacks JS, Warner RR, et al. Early and late results of valvular surgery for carcinoid heart disease. J Am Coll Cardiol. 2008;51:1507-9.

3. Gustafsson BI, Hauso O, Drozdov I, Kidd M, Modlin IM. Carcinoid heart disease. Int J Cardiol. 2008;129:318-24. Epub 2008 Jun 20.

4. Bhattacharyya S, Toumpanakis C, Caplin ME, Davar J. Analysis of 150 patients with carcinoid syndrome seen in a single year at one institution in the first decade of the twenty-first century. Am J Cardiol. 2008;101:378-81.

5. Mansencal N, Mitry E, Forissier JF, Martin F, Redheuil A, Lepere C, et al. Assessment of patent foramen ovale in carcinoid heart disease. Am Heart J. 2006;151: 1129.e1-6.

\title{
Successful resection of localized pulmonary mucormycosis after bone marrow transplantation using a virtual 3-dimensional pulmonary model on a personal computer
}

\author{
Hideyuki Maeda, MD, Masato Kanzaki, MD, Tamami Isaka, MD, PhD, and Takamasa Onuki, MD, PhD, \\ Tokyo, Japan
}

Mucormycosis is a rare and fatal infectious disease. Pulmonary mucormycosis most often occurs in patients with neutropenia, immune deficiencies, malignant disease, malnutrition, diabetes, and trauma, as well as in patients undergoing organ transplantation or chelation therapy involving deferoxamine. ${ }^{1,2}$ For control of the underlying disease, a polyene administration and surgical resection of infected lung segments may prove helpful. We report a case of localized pulmonary mucormycosis after bone marrow transplantation that was successfully resected using a virtual 3-dimensional pulmonary model on a personal computer.

\footnotetext{
From the Department of Surgery I, Tokyo Women's Medical University, Tokyo, Japan.

Disclosures: None

Received for publication April 30, 2010; accepted for publication May 11, 2010; available ahead of print June 11, 2010.

Address for reprints: Masato Kanzaki, MD, Department of Surgery I, Tokyo Women's Medical University, 8-1 Kawada-cho, Shinjuku-ku, Tokyo 162-8666, Japan (E-mail: kanzaki@chi.twmu.ac.jp).

J Thorac Cardiovasc Surg 2010;140:1434-6

$0022-5223 / \$ 36.00$

Copyright (c) 2010 by The American Association for Thoracic Surgery

doi:10.1016/j.jtcvs.2010.05.007
}

\section{CLINICAL SUMMARY}

A 28-year-old man, treated with allogenic bone marrow transplantation for acute lymphatic leukemia in March 2009, had progressive dyspnea and productive cough in May 2009. Chest radiography and computed tomography (CT) revealed a fungus ball in the left upper lobe of the lung (Figure 1, A). Mucor was detected by bronchoscopic biopsy. When liposomal amphotericin B (L-AMB) was administered, the size of the fungus ball reduced immediately (Figure 1,B). However, because the patient became resistant to L-AMB, he was referred to our division for surgery for pulmonary mucormycosis. Preoperative blood chemistry analysis showed pancytopenia and renal insufficiency (the serum creatinine level $1.94 \mathrm{mg} / \mathrm{dL}$ ) caused by ongoing L-AMB administration. Chest CT demonstrated an 18-mm cavitary mass in $\mathrm{S} 1+2 \mathrm{c}$ of the left lung. For preoperative simulation of surgical resection, we used free software application such as CTTRY, where we could mark on pulmonary arteries, veins, bronchi, and fungus ball of the images on high-resolution CT images. With 60 2-mm highresolution CT images of the fungus ball and hilum, in DICOM (Digital Imaging and Communications in Medicine) format, we obtained 3-dimensional images for a patient 